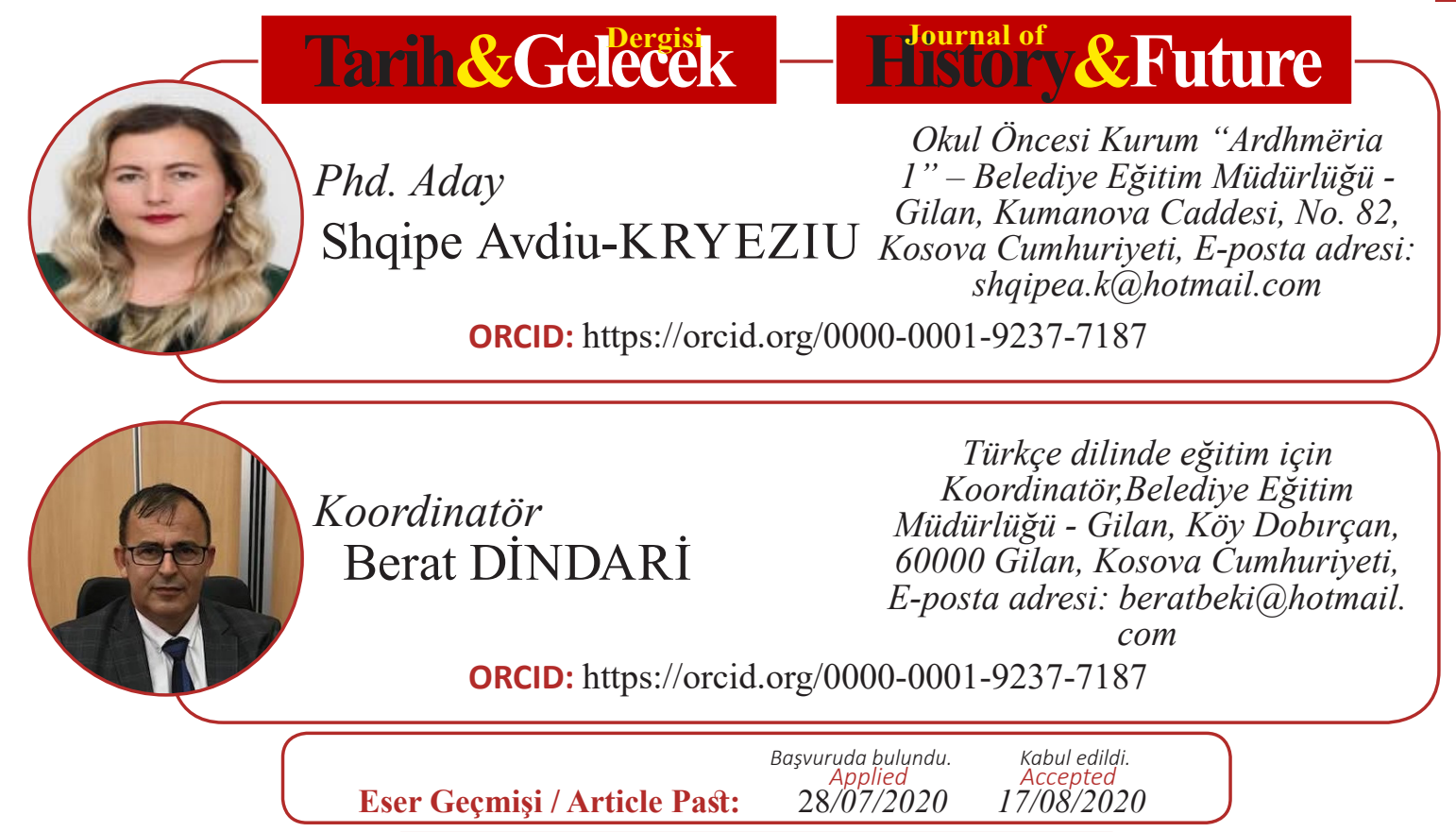

Araştırma Makalesi

DOI: http://dx.doi.org/10.21551/jhf.758243

Research Paper

Orjinal Makale / Orginal Paper

\title{
Gilan Belediyesine Özel Önem Verilerek Kosova'da Türk Eğitiminin Tarihsel Gelişimi
}

\author{
Historical Development of Turkish Education in Kosovo \\ Specifically in The Municipality Of Gjilan
}

\section{$\ddot{O} \mathbf{z}$}

Kosova Cumhuriyeti, yeni ve modern bir devlet olarak, kapsayıcı eğitim-öğretim kurumlarının demokratikleşmesi için tanımlanmıştır. Kosova'daki Türk okullarının ilk açılışından bu yana eğitim sisteminin yıllar içindeki gelişimi karşılaştırılırsa, Kosova'daki eğitim sistemi birçok değişikliğe uğramıştır.

1999'dan beri Kosova'nın Sırp işgalcilerden kurtarılmasıyla birlikte, eğitim sistemi de değişmiştir, böylece topluluklar eğitim sisteminin, eğitim yasalarının, dahil edilmenin, alt, orta ve yüksek eğitimin eşit parçalarıdır, bu yüzden onlar bu sistem içinde eşit olduğunu söyleyebiliriz.

Kosova `nın eğitim sistemine seminerlerle, didaktik araçlarla, tek kelime ile genel olarak Kosova eğitimine yardım eden Türk devletinin katkısı bahsetmeye değer.

Gilan Belediyesi, eğitim sisteminde iyi entegre olmuş bir Türk topluluğuna sahiptir, Kosova'daki Türk KFOR aracılığıyla Türk devleti ile özel bir işbirliğinin yanı sıra Türkiye'deki Türk belediyeleriyle kardeștir.

Bu yazıda, temel olarak 1857'den günümüze 2020'nin son istatistikleriyle Türk eğitiminin gelişimine odaklandık.

Anahtar Kelimeler: eğitim, topluluk, türk, Gilan, entegrasyon.

\section{Abstract}

The Republic of Kosovo, as a new and modern state, is determined for inclusive education and democratization of educational institutions. Comparing the development of the education system over the years since the first opening of Turkish schools in Kosovo until today, the education system in Kosovo has undergone many changes.

Since 1999, with the liberation of Kosovo from the Serbian occupiers, the education system has changed. Communities are an equal part of the education system, the education legislature, inclusion, lower, secondary and higher

ATIF: KRYEZİU Shqipe Avdiu, DİNDARİ Berat, “Gilan Belediyesine Özel Önem Verilerek Kosova'da Türk Eğitiminin Tarihsel Gelişimi”, Tarih ve Gelecek Dergisi, 6/3 (Eylül 2020), s. (000-000) 
education, so it can be said that they are equal within this system.

It is worth mentioning the contribution of the Turkish state in helping the education system with trainings, didactic tools, etc. In a word, they have generally helped Kosovar education.

In the municipality of Gjilan, the Turkish community is well-integrated in the education system. There is a special cooperation with the Turkish state through the Turkish KFOR in Kosovo, as well as twinning with Turkish municipalities in Turkey.

In this paper, we have mainly focused on the development of Turkish education from 1857 to the present day with the latest statistics of 2020 .

Keywords: education, community, Turkish, Gjilan, integration.

\section{Giriş}

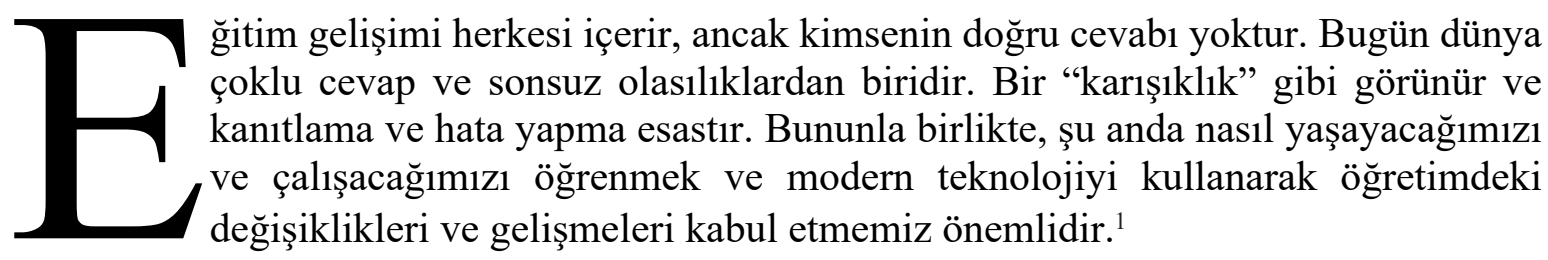

Kosova'da Türkçe eğitiminin gelişimi - Kosova Osmanlı İmparatorluğu yönetimindeydi ve İstanbul'da modern okulların açılmasından sonra 1857 'de Kosova'daki ilk modern (laik) Türk okulları açıldı. ${ }^{2}$

1900 yılında Kosova şehirlerinde önemli sayıda Türk öğrenci vardı: Priştine’de 196 öğrenci vard,, Vuitri de 55 öğrenci, Mitroviça`da 43 öğrenci, Gilan`da 55 öğrenci, Prizren`de 69 öğrenci, Yakova` da 137 öğrenci, Türkçe öğrenen Arnavut öğrenciler dahil edilmeden. ${ }^{3}$

Kosova'da Arnavut okullarının açı1ışı XIX-cu yüzyıl boyunca başlıyor, sırasıyla AvusturyaMacaristan yönetimi altındaki Birinci Dünya Savaşıyla, Prizren, Yakova ve Ipek’teki Katolik okullarının yanı sıra Prizren'deki erkek ve kız çocukları için ilkokulun açılmasıyla. Kosova'da, ilk Arnavut okulu 1905'te Viti belediyesindeki Stubıll köyünde açıldı.

Arnavutluk'un bağımsızlığından sonra, Birinci Dünya Savaşı sırasında, bu dönemde Kosova'da 100 öğretmen ve 4.000 öğrenci ile 50'ye yakın Arnavutça dilinde okul açıldı. ${ }^{4}$

20-ci yüzyılın başlarında Kosova'da gelişen modern Türk eğitimi, 1912'de Balkan Savaş1 ile sona erdi. 1912'de Balkan Savaşları İttifakı tarafından mağlup edilen Osmanlı İmparatorluğu, Kosova'yı Sırbistan Krallığı'na bırakmak zorunda kaldı. Bu kayıpla Kosova'da yaşayan Türkler hâkim durumdan ulusal azınlığa düştü ve kendi dillerinde eğitim almak için etkili yetkilerini kaybettiler. ${ }^{5}$

İki dünya savaşı arasındaki dönemde Kosova, Sırp-Hırvat-Sloven yönetimi altında kaldı, Kosova'da bu süre zarfında Arnavutça dilinde okullar yoktu, eğitim ve Arnavutça dilinin kullanımını Sirbistan yasalarla yasakladı, bu az sayıda okullar bile Sirp-Hırvat dilinde ve dini okullarıydı.. İkinci Dünya Savaşı'ndan sonra bile, 1956'ya kadar Arnavut okulları yoktu ve aynı yıl, Arnavutça

\footnotetext{
Zhvillimi i shkathtësive të shekullit 21 në klasat me nxënësin në qendër, (Kosovë: USAID, 2013), f.16

Kosova'da Türkçe Eğitim (1951-2016) Monografi, (Prizren: Kosova Türk Öğretmenler Derneği, 2016), f.13

Kosova'da Türkçe Eğitim (1951-2016) Monografi, (Prizren: Kosova Türk Öğretmenler Derneği, 2016), f.17

Hajrullah Koliqi, Historia e arsimit dhe e Mendimit Pedagogjik Shqiptar, (Prishtinë: Libri Shkollor,2002), f. 336

5 Kosova'da Türkçe Eğitim (1951-2016) Monografi, (Prizren: Kosova Türk Öğretmenler Derneği, 2016), f.20
} 
dilinde okullar resmi olarak Kosova'nın bazı merkezlerinde ve köylerinde açıldı. ${ }^{6}$

1990'larda, Kosova haksız yere Arnavutluk eğitim hakkından mahrum bırakıldı, Kosova' daki öğretmenler ve öğrenciler zorla eğitim kurumlarından atıldı, ancak bilgi arama ve öğretmenlerin Kosova'daki öğrencilere bilgi sağlama çabaları Sırp işgal sistemine meydan okudu ve öğrencileri öğretmek için okul-evleri açtılar. ${ }^{7}$

Yeni üniversite öncesi eğitim sistemi iki ana hedefi karşılayacak şekilde düzenlenmiştir: üniversitede devam eden çalışmalar için gerekli teorik temeli oluşturmak ve işgücü piyasası için yeterli mesleki yeterliliği oluşturmak. Yasa, 6 yaşındaki çocukların hepsinin ilkokul birinci sınıfa gitmesi gerektiğini öngörüyor. Kosova'daki eğitim reformunun ilk adımları, 2000/2001 öğretim yılında 6 yaşından itibaren çocukların örgün eğitiminin başlamasıyla işaretlenmiştir. Kosova'da, ilkokula başlama yaşı 6 yaşında, sırasıyla birinci sınıf, dünyanın farklı ülkeleri, birkaç istisna dışında, bu eğitimin başlangıç standardına saygı duyuyor. Kosova, ilkokul eğitim sisteminin Kosovalı çocukların yaşı için bilgi ve becerilerin başarılı bir şekilde kazanılması için en uygun 5 yıl süreceği konusunda kararlı. Bu seviyedeki eğitim programları öğrencilere okuma, yazma, matematik ve teknolojinin kullanımı hakkında temel bilgiler edinme firsatı sunar. Ayrıca tarih, coğrafya, doğa bilimleri, sosyal bilimler, sanat ve müzik hakkında temel bilgiler edinirler. ${ }^{8}$ Müfredat esas olarak bir öğretmen tarafından yönetilir, ancak belirli dersler için, ilgili alandaki uzman öğretmenler de devreye girer, beşinci sınıf öğrencileri BİT’i müfredat içinde ayrı bir ders olarak öğrenirler. Bu seviyede müfredat herkes için aynıdır, oryantasyon yolları oluşturma ihtiyacı değerlendirilmemiştir.

Kosova artık en gelişmiş ülkelerde olduğu gibi nüfusun bilgi ve iletişim teknolojilerini yüksek oranda kullandığı bir ülkedir, diğer yandan Kosova okullarında 46 öğrenciye bir bilgisayar bulunmaktadır, bu arada\% 50'nin üzerindeki öğretim elemanlarının bir kısmı ECDL için eğitilmiştir. Böyle bir durum, sınıfta teknolojinin uygulanmasına yönelik daha hızlı bir hareket gerektirir, çünkü bunun tersi, öğrencilerin geleceği için okulun önemini azaltabilir. Önümüzdeki beş yıl içinde teknoloji kullanımının, şu an için öngörülemeyen başka boyutlar kazanması beklenmektedir. Bu nedenle, teknolojinin okullara daha hızlı entegrasyonu lehine Kosova Eğitim Stratejik Planında daha sonra değişiklik yapılması gerekebilir. ${ }^{9}$

Kosova'daki eğitim sistemi aşağıdaki şekilde yapılandırılmıştır:

Okul Öncesi Eğitim (sıfır ila 6 yaş arası çocuklar);

İlköğretim (1-5 sınıflar, 6-10 yaş arası çocuklar);

Alt Orta Öğretim (6-9 sınıflar, 11-14 yaş arası çocuklar);

Yüksek Orta Öğretim (10-12 sınıflar, 15-18 yaş arası çocuklar) ve

Yüksek Öğretim. ${ }^{10}$

Biz Türk toplumunun Kosova'daki eğitim sistemine entegrasyonunu ve Türk öğretmenlerin Kosova eğitim sisteminde çağdaş öğretime katkısını incelemeye aldık.

Çağdaş bir eğitim kurumu olarak okul, ilk etapta entelektüel gelişim ve öğrencilerin hazırlanması için ulusal ilginin stratejik önemini ve açık ve kaliteli toplum için genel dönüşümü

\footnotetext{
Hajrullah Koliqi, Historia e arsimit dhe e Mendimit Pedagogjik Shqiptar, (Prishtinë: Libri Shkollor,2002), f.479

Bajram Shatri, Arsimi Shqip në Kosovë 1990-1999, (Prishtinë: Libri Shkollor, 2010), f. 137

Clasifying Education Programs Manual for ISCED 97 Implementation in OECD countries, (Prishtinë: OECD 1999), f. 32.

Plani Strategjik i Arsimit në Kosovë 2017-2021, (Prishtinë: MASHT, 2016), f. 17

Plani Strategjik i Arsimit në Kosovë 2017-2021, (Prishtinë: MASHT, 2016), f. 20
} 
stratejik olarak geliştirmeye yöneliktir. Bu hedeflere ulaşmak için okulun yenilenmesi ve modern bir okula doğru ilerlemesi gerektiği bilinen bir gerçektir. ${ }^{11}$

Çağdaş okula ve öğretime yönelik değişiklikler, bazı bölüm ve düzeylerdeki değişikliklere odaklanır: müfredat; öğretim süresince öğretim teknolojilerinin ve çağdaş öğretim yöntemlerinin kullanılması. ${ }^{12}$

Geçen yüzyılda teknolojide çok hızlı bir gelişme oldu ve öğrenciler tarafından kullanımında, çocukların düşünme, öğrenme, geliştirme ve davranış biçimlerini açıkça şekillendiren, teknolojinin çok yönlü doğasını gören bir gerçek, günümüzde çocuk gelişiminde çok normaldir. Bazı teknoloji formlarının, dönüştürmek üzere tasarlandıkları davranışlar üzerinde hiçbir etkisi yoktur, ancak bazı durumlarda teknolojinin etkileri açıktır. Bütün bunlar, gelişimi sırasındaki çocuk gelişimi ve teknoloji gelişimi alanlarıyla ilgilidir. ${ }^{13}$

1951'den itibaren Yugoslavya Türkiye ile politikalarını değiştirdi ve bu değişiklikle bu yıldan başlayarak Kosova'da Türklerin varlığı bilinmeye başladı. 20 Mart 1951'de Kosova'da Türkçe dilinde okulların açılmasına karar verildi. 1951/1952 akademik yıllarında Prizren, Priştine, Gilan, Mitroviça kentlerinde Türk ilköğretim okulları açıldı. ${ }^{14}$

Davranış dünyamızda büyük değişikliklerveyenizorluklarortaya çıkıyor. NATOkuvvetlerinin 1999'da müdahalesinin ardından, genç nesillerin bu zorluklarla başa çıkmasına yardımcı olmak amacıyla Kosova'da kurulan BM Geçici Yönetim Misyonu (UNMIK) tarafından yeni eğitim ve yönetim sistemi geliştirildi. UNMIK yönetimi Kosova için Yeni Müfredat Çerçevesini tanıttıktan ve 6 yaşını doldurmuş çocukların 2002 yılında ilkokul birinci sınıfa kaydolduktan sonra, Kosova İlköğretim ve Ortaöğretim Kanunu (2002/2 say1lı Kanun), Yeni eğitim sistemi Kosova'da 2002/03 öğretim yılında tanıtıldı. Yeni eğitim sistemine göre, öğrenciler ilkokulun ilk sınıfına önceki yedi yerine altı yaşında kaydolmaktadır, 2002/2003 öğretim yılından itibaren öğrenciler birinci sınıfa bir yıl daha genç girmekte, üniversite öncesi eğitim $5+4+3$ ve 4 yıl olarak düzenlenmiştir, $4+4$ + 4 yerine ve yüksek öğretimde Bologna eğitim sistemi olarak. Kosova'da 2002/03 öğretim yılında uygulanmaya başlanan yeni eğitim reformu ile zorunlu ilköğretim, sekiz ila dokuz yıl hariç ek olarak Eğitim, Bilim ve Teknoloji Bakanlığı tarafından hazırlanan yeni müfredat ile uygulanmıştır. ${ }^{15}$

1999'dan 2008'e kadar, Türk toplumu için Kosova'da eğitim sağlamanın ve dillerini kullanma hakkını garanti etmenin yanı sıra, 2001 yılında Kosova Türk Müfredat Çerçevesi, okulöncesi, ilkokul ve ortaokul eğitim planları ve programları Türkçe dilinde yayınlandı. ${ }^{16}$ Kosova' daki bu olumlu gelişmeler sayesinde Türkiye Cumhuriyeti'nin desteğiyle eğitim kalitesi daha yüksek bir düzeye çıkarılmıştır. 1999/2000 yıllarında Kosova'da Türkçe eğitimi ve öğretimi ilkokullarda (sekiz y1llık) 2029 öğrenciye sahipti. ${ }^{17}$

Eğitim, Bilim ve Teknoloji Bakanlığı'nın kararı ile 2002 yılında Priştine Üniversitesi'nde Eğitim Fakültesi kuruldu, Bu fakültedeki öğretim: 18.11.2002 tarihinde başlad1, Eğitim Fakültesinin merkezi Priştinededir, Eğitim Fakültesi kapsamında, kendi proğramlarıyla Priştine, Gilan, Yakova

11 Xheladin Murati, Pedagogjia e përgjithshme, (Shkup: Logos-A, 2004), f. 419

12 Xheladin Murati, Pedagogjia e përgjithshme, (Shkup: Logos-A, 2004), f. 394

13 Hesiona Havaraj, Teknologjia, ndikuese në dobësimin e aftësive komunikuese te fëmijët, International Institute for PrivateCommercial- and Competition Laë(IIPCCL), (Tiranë: 2018), f. 315

14 Kosova'da Türkçe Eğitim (1951-2016) Monografi, (Prizren: Kosova Türk Öğretmenler Derneği, 2016), f.26

15 Kosova'da Türkçe Eğitim (1951-2016) Monografi, (Prizren: Kosova Türk Öğretmenler Derneği, 2016), f.31

16 Kosova'da Türkçe Eğitim (1951-2016) Monografi, (Prizren: Kosova Türk Öğretmenler Derneği, 2016), f.34

17 Kosova'da Türkçe Eğitim (1951-2016) Monografi, (Prizren: Kosova Türk Öğretmenler Derneği, 2016), f.35 
ve Prizren'deki Kosova'nın dört bölgesel merkezi ile faaliyet gösterdiler. 2003/2004 akademik yılında Türkçe öğretim öğrencileri de Eğitim Fakültesi'nde okudu. ${ }^{18} 2009$ yılında kurulan Prizren Üniversitesi "Ukshin Hoti” tarafından Türkçe dilinde eğitim verilmektedir, bu üniversitenin Eğitim Fakültesinde Türkçe dilinde eğitim verilmektedir. ${ }^{19}$

Kosova Cumhuriyeti’nde üniversite öncesi eğitim ile ilgili olarak, Eğitim, Bilim ve Teknoloji Bakanlığı, Türkçe (ve diğer topluluklara da) üniversite öncesi eğitim için bir müfredat geliştirmiştir. Türk dilinde üniversite öncesi eğitim, Kosova Türk nüfusunun bulunduğu altı belediyeden beşinde verilmektedir. ${ }^{20}$

Tablo 1. Kosova'daki etnik Arnavut ve Türk üyeliğine göre öğrenci sayısı

\begin{tabular}{|c|c|c|c|}
\hline Öğretim yılı & Arnavut & Türk & Referanslar \\
\hline $2015 / 2016$ & 359.649 & 2.919 & İstatistik verileri $2015 / 16^{1}$ \\
\hline $2016 / 2017$ & 354.789 & 2.783 & İstatistik verileri $2016 / 17^{2}$ \\
\hline $2017 / 2018$ & 350.273 & 2.756 & İstatistik verileri $2017 / 18^{3}$ \\
\hline $2018 / 2019$ & 341.463 & 2.760 & İstatistik verileri $2018 / 19^{4}$ \\
\hline $2019 / 2020$ & 331.132 & 2.754 & İstatistik verileri $2019 / 20^{5}$ \\
\hline
\end{tabular}

Kosova'da, eğitimde demokratik değerler, politikalar ve uygulamalar açısından Kosova'nın şu anda bulunduğu en az 4 alan vardır:

Çocuk haklarının korunması, dahil edilmesi ve ayrımcılık yapılmaması;

Demokratik değerlerin ve müfredat hedeflerinin varlığg;

Öğretmen politikalarında kapsayıcı eğitimin ve demokratik okulun kriter / şartlarının varlığı;

Okul gelişiminde kapsayıcı eğitim ve demokratik okul kriterlerinin varlığı ve kalite güvencesinde okul politikaları ve Kosova'daki tüm topluluklar için eşit erişim. ${ }^{21}$

Tüm çocukların temel, zorunlu ve kaliteli eğitime eşit haklara sahip olduğu Kosova'daki Müfredat Çerçevesi (kapsayıcılık) ilkelerine dayanmaktadır. Tüm çocukların yaş, cinsiyet, etnik köken, 1rk, din, sağlık, sosyal, ekonomik ve çocukların yetenek ve yeteneklerinden bağımsız olarak öğrenme sürecine erişim, özveri, artan katılım ve kalite hakkı vardır. Kapsayıcı eğitim, ayrım gözetmeksizin tüm çocuklar için tanınma, kabul ve saygı sağlar. ${ }^{22}$

Kosova'daki eğitim sisteminde Türkçe dil öğretimi genellikle yaşadıkları belediyelerdeki topluluklar tarafından kullanılabilirken, belediyeler öğrenci sayısı belirlenen minimumdan düşük olsa bile eğitim sunmaktadır. ${ }^{23}$

Kosova Cumhuriyeti'ndeki topluluklar Anayasa ve ilgili yasalar tarafindan kendi dillerinde

18 Universiteti i Prishtinës - University of Prishtina 1970-2005, (Monografi), (Prishtinë: Universiteti i Prishtinës, 2005), f. 198

19 https://uni-prizren.com/sq/fakulteti-i-edukimit, shfletuar më: 21.06.2020

20 Qasja e komuniteteve në arsimin parauniversitar në Kosovë, (Prishtinë: OSBE, 2018), f. 13

21 Udhërrëfyes për politikat që mbështesin kulturën demokratike në shkollë, Horizontal Facility for Western Balkans and Turkey, (Prishtinë: Këshilli i Evropës , 2018), f. 22

22 Korniza Kurrikulare e Arsimit Parauniversitar të Republikës së Kosovës, (Prishtinë: MASHT, 2016), f. 25

23 Raporti i Vlerësimit të Drejtave të Komuniteteve Edicioni i Katërt, (Prishtinë: OSBE, 2015), f. 22 
eğitim hakkı ile güvence altına alınmıştır. Kosova Cumhuriyeti'ndeki Toplulukların ve Üyelerinin Haklarının Korunması ve Geliştirilmesi Kanunu'na göre: “Topluluklara mensup herkes, seçtikleri Kosova'nın resmi dillerinden birinde, her düzeyde kamu eğitimi alma hakkına sahiptir. Topluluklara mensup kişiler, resmi bir dil olmasa bile, kendi dillerinde okul öncesi, ilkokul ve ortaokul eğitimi alma hakkına sahiptir. Hükümet, topluluk dillerinde faaliyet gösteren özel sınıfların veya okulların kurulması için makul ve uygulanabilir eşikler belirler. Bu tür sınıflar veya okullar için minimum eşik, normalde okullar ve sınıflar için belirlenen eşiklerden daha düşüktür. Maksimum eşikler, okul sınıfları için normal olarak belirlenen eşiklere karşılık gelecektir. Bu, kanunla düzenlenir". ${ }^{24}$

Gilan Belediyesinde Türkçe Eğitimi - Gilan Belediyesi Eğitim Müdürlüğüne göre, Türk öğrenciler aşağıdaki okullarda eğitime devam ediyorlar: Gilan'daki "Musa Zajmi” İlk ve Orta öğretim okulu ve Dobırçan köyünde "Nazım Hikmet” İlk ve Orta öğretim okulu, ve Gilan'daki Orta Yüksek Okulu, Lisesi "Xhavit Ahmeti”. ${ }^{25}$

Aşağıdaki tabloda, Gilan okullarındaki öğrencilerin (sayı) sistemleştirilmesi için veriler sunulmaktadır.

Tablo 2. Gjilan Belediyesi İlköğretim, Ortaöğretim ve Lise öğretimi Okullarındaki Türk öğrenci sayısı

\begin{tabular}{|l|l|l|l|}
\hline Öğretim yılı & Yaşama yeri & Türkler & \multicolumn{1}{c|}{ Referanslar } \\
\hline $2015 / 2016$ & Gilan & 62 & Kosova'da Eğitim İstatistikleri 2015/2016 \\
\hline $2016 / 2017$ & Gilan & 49 & Kosova'da Eğitim İstatistikleri 2016/20177 \\
\hline $2017 / 2018$ & Gilan & 52 & Kosova'da Eğitim İstatistikleri 2017/2018 \\
\hline $2018 / 2019$ & Gilan & 52 & Kosova'da Eğitim İstatistikleri 2018/20199 \\
\hline $2019 / 2020$ & Gilan & 45 & Kosova'da Eğitim İstatistikleri 2019/202010 \\
\hline
\end{tabular}

Gjilan Belediyesi'ndeki eğitim sürecinin geliştirilmesinde, Türk kuruluşu "TíKA" tarafından bu süreçte yaptığı yardımla, "MESAZHI" gazetesinin web sitesinde belirtildiği gibi teknolojik araçlara özel vurgu yapılarak özel bir rol oynand 2016 yılında $^{26}$, Türk Hükümet Örgütü "TIKKA", Gilann Belediyesi ile yıllar içinde işbirliğini sürdürdü, 2019'da birkaç okul öncesi sınıfı yeniledi vb. ${ }^{27}$

\section{Sonuçlar}

Tarihsel ve pedagojik literatürün yanı sıra Kosova Cumhuriyeti Eğitim, Bilim ve Teknoloji Bakanlığı'nın verilerine dayanarak, tarihsel gelişim bağlamında Kosova'daki eğitim sisteminin pedagoji/müfredat yanı sıra yapısal açısından da önemli değişikliklere uğradığı sonucuna vardık.

Toplulukların Kosova'daki eğitim sistemine dahil edilmesi tatmin edicidir ve özellikle Türk toplumu içinde ve Kosova kurumları arasındaki işbirliği son derece tatmin edicidir.

Makalede yer alan yukarıdaki istatistiklerde, Türk toplumunun tüm öğrencilerinin Kosova

24 Ligji NR. 03/L-047, Për Mbrojtjen dhe Promovimin e të Drejtave të Komuniteteve dhe Pjesëtarëve të Tyre në Republikën e Kosovës, Neni 8, (Prishtinë: Kuvendi i Republikës së Kosovës, 2008)

25 Drejtoria Komunale e Arsimit në Gjilan, Zyra për komunitete, (Gjilan më: 15.06.2020)

26 https://www.mesazhi.com, të datës 12 tetor 2016, shfletuar më: 21.06.2020

27 Drejtoria Komunale e Arsimit në Gjilan, Zyra për komunitete, (Gjilan më: 15.06.2020) 
Cumhuriyeti'nde temel eğitime dahil edildiğini bulduk.

\section{Kaynaklar}

Shatri, Bajram. Arsimi Shqip në Kosovë 1990-1999, (Prishtinë: Libri Shkollor, 2010)

Drejtoria Komunale e Arsimit në Gjilan, Zyra për komunitete, më: 15.06.2020

Koliqi, Hajrullah. Historia e arsimit dhe e Mendimit Pedagogjik Shqiptar, (Prishtinë: Libri Shkollor, 2002)

Korniza Kurrikulare e Arsimit Parauniversitar të Republikës së Kosovës, (Prishtinë: MASHT, 2016)

Kosova'da Türkçe Eğitim (1951-2016) Monografi, (Prizren: Kosova Türk Öğretmenler Derneği, 2016)

Ligji NR. 03/L-047, Për Mbrojtjen dhe Promovimin e të Drejtave të Komuniteteve dhe Pjesëtarëve të Tyre në Republikën e Kosovës, Neni 8, (Prishtinë: Kuvendi i Republikës së Kosovës, 2008)

Clasifying Education Programs Manual for ISCED 97 Implementation in OECD countries, (Prishtinë: OECD 1999)

Plani Strategjik i Arsimit në Kosovë 2017-2021, (Prishtinë: MASHT, 2016)

Qasja e komuniteteve në arsimin parauniversitar në Kosovë, (Prishtinë: OSBE, 2018)

Raporti i Vlerësimit të Drejtave të Komuniteteve Edicioni i Katërt, (Prishtinë: OSBE, 2015)

Statistikat e Arsimit në Kosovë 2015/2016, (Prishtinë: MASHT, 2016)

Statistikat e Arsimit në Kosovë 2016/2017, (Prishtinë: MASHT, 2017)

Statistikat e Arsimit në Kosovë 2017/2018, (Prishtinë: MASHT, 2018)

Statistikat e Arsimit në Kosovë 2018/2019, (Prishtinë: MASHT, 2019)

Statistikat e Arsimit në Kosovë 2019/2020, (Prishtinë: MASHT, 2020)

Shënime statistikore 2018/2019, Të dhëna mbi arsimin parauniversitar, Sistemi i Menaxhimit të Informatave në Arsim, (Prishtinë: MASHT, 2018)

Shënime statistikore 2019/2020, Të dhëna mbi arsimin parauniversitar, Sistemi i Menaxhimit të Informatave në Arsim, (Prishtinë: MASHT, 2019)

Shënime statistikore 2015/2016, Të dhëna mbi arsimin parauniversitar, Sistemi i Menaxhimit të Informatave në Arsim, (Prishtinë: MASHT, 2015)

Të dhëna mbi arsimin, Shënime statistikore 2017/2018, Arsimi parauniversitar, Sistemi i Menaxhimit të Informatave në Arsim, (Prishtinë: MASHT, 2017)

Të dhëna mbi arsimit, Shënime statistikore 2016/17, Arsimi Parauniversitar, Sistemi i Menaxhimit të Informatave në Arsim, (Prishtinë: MASHT, 2016)

Udhërrëfyes për politikat që mbështesin kulturën demokratike në shkollë, Horizontal Facility for Ëestern Balkans and Turkey, (Prishtinë: Këshilli i Evropës, 2018)

Universiteti i Prishtinës - University of Prishtina 1970-2005, (Monografi), (Prishtinë: Universiteti i Prishtinës, 2005)

Murati, Xheladin. Pedagogjia e përgjithshme, (Shkup: Logos-A, 2004) 
Zhvillimi i shkathtësive të shekullit 21 në klasat me nxënësin në qendër, (Kosovë: USAID, 2013)

Havaraj, Hesiona. Teknologjia, ndikuese në dobësimin e aftësive komunikuese te fëmijët, International Institute for Private- Commercial- and Competition Laë (IIPCCL), (Tiranë:2018)

\section{Internet kaynakları}

https://uni-prizren.com/sq/fakulteti-i-edukimit, shfletuar më: 21.06.2020

https://www.mesazhi.com, të datës 12 tetor 2016, shfletuar më: 21.06.2020

\section{(Tablo içindeki dipnotlar)}

1 Shënime statistikore 2015/16, Arsimi Parauniversitar, Sistemi i Menaxhimit të Informatave në Arsim, (Prishtinë: MASHT, 2015), f. 2

2 Të dhëna mbi arsimit, Shënime statistikore 2016/17, Arsimi Parauniversitar, Sistemi i Menaxhimit të Informatave në Arsim, (Prishtinë: MASHT, 2016), f. 2

3 Të dhëna mbi arsimin, Shënime statistikore 2017/2018, Arsimi Parauniversitar, Sistemi i Menaxhimit të Informatave në Arsim, (Prishtinë: MASHT, 2017), f. 2

4 Shënime statistikore 2018/2019, Të dhëna mbi arsimin parauniversitar, Sistemi i Menaxhimit të Informatave në Arsim, (Prishtinë: MASHT, 2018), f. 2

5 Shënime statistikore 2019/2020, Të dhëna mbi arsimin parauniversitar, Sistemi i Menaxhimit të Informatave në Arsim, (Prishtinë: MASHT, 2019), f. 2

6 Statistikat e Arsimit në Kosovë 2015/2016, (Prishtinë: MASHT, 2016), f. 31

7 Statistikat e Arsimit në Kosovë 2016/2017, (Prishtinë: MASHT, 2017), f. 32

8 Statistikat e Arsimit në Kosovë 2017/2018, (Prishtinë: MASHT, 2018), f. 44

9 Statistikat e Arsimit në Kosovë 2018/2019, (Prishtinë: MASHT, 2019) f. 32

10 Statistikat e Arsimit në Kosovë 2019/2020, (Prishtinë: MASHT, 2020), f. 32 